\title{
Dobutamine Tartrate
}

National Cancer Institute

\section{Source}

National Cancer Institute. Dobutamine Tartrate. NCI Thesaurus. Code C65452.

The tartrate salt form of dobutamine, a synthetic catecholamine with sympathomimetic activity. Dobutamine primarily binds to and stimulates beta-1-adrenergic receptors located in the myocardium. As a result, it leads to a positive inotropic effect and increases in cardiac output. 